\title{
Why should people with type 1 diabetes exercise regularly?
}

\author{
Roberto Codella ${ }^{1}$, Ileana Terruzzi ${ }^{2}$, Livio Luzi ${ }^{1,3}$ \\ ${ }^{1}$ Department of Biomedical Sciences for Health, University of Milan, Milan, Italy \\ ${ }^{2}$ Diabetes Research Institute, Metabolism, Nutrigenomics and Cellular Differentiation Unit, \\ San Raffaele Scientific Institute, Milan, Italy \\ ${ }^{3}$ Metabolism Research Center, IRCCS Policlinico San Donato, San Donato Milanese, Italy
}

Manuscript counts:

$\begin{array}{lc}\text { Abstract } & 173 \text { (words) } \\ \text { Body text } & 5035 \text { (words) } \\ \text { References } & \frac{119}{2} \\ \text { Tables } & 3 \\ \text { Figures } & \end{array}$

Running head: Exercise in type 1 diabetes

\section{Corresponding author:}

Roberto Codella, $\mathrm{PhD}$

Department of Biomedical Sciences for Health

University of Milan

Via F.1li Cervi 93, 20090 Segrate (Milano) - Italy

Phone: $\quad+390250330300$

Fax: $\quad+390250315152$

E-mail: roberto.codella@unimi.it 


\begin{abstract}
Plethoric evidence reminds of the protective effects of exercise against a number of health risks, across all ages, in the general population. The benefits of exercise for individuals with type 2 diabetes are indisputable. An in-depth understanding of energy metabolism has reasonably entailed exercise as a cornerstone in the lifestyle of almost all subjects with type 1 diabetes. Nevertheless, individuals with type 1 diabetes often fail in accomplishing exercise guidelines and they are less active than their peer without diabetes. Two major obstacles are feared by people with type 1 diabetes who wish to exercise regularly: management of blood glucose control and hypoglycemia. Nowadays strategies, including glucose-monitoring technology and insulin pump therapy, have significantly contributed to the participation in regular physical activity, and even in competitive sports, for people with type 1 diabetes. Novel modalities of training, like different-intensity, interspersed exercise, are as well promising. The beneficial potential of exercise in type 1 diabetes is multi-faceted and it has to be fully exploited because it goes beyond the insulin-mimetic action, possibly through immunomodulation.
\end{abstract}

\title{
Keywords:
}

Glucose monitoring, Insulin pump, Autoimmunity, Hypoglycemia, Immunomodulation

\footnotetext{
Abbreviations:

CGM, continuous glucose monitoring; CSII, continuous subcutaneous insulin infusion; CVD, cardiovascular disease; GLP-1, glucagon-like peptide-1; IL-6, interleukin 6; IMCL, intramyocellular lipid content; IT, islet transplantation; MDII, multiple daily insulin injections; NEFA, non-esterified fatty acid; SMBG, self-monitoring blood glucose; T1D, type 1 diabetes.
} 


\section{From type 2 to type 1 exercise-recommendations: over the guidelines}

In 1993, Kahn et al. first described the hyperbolic relationship between $\beta$-cell function and insulin sensitivity [1]. Physical exercise enables the achievement of better positions on the glucose-tolerance curve by ameliorating insulin sensitivity in any subject, either with type 2 (T2D) or type 1 diabetes (T1D). Traditionally, physical exercise is promoted in T2D where insulin action is deficient in the context of insulin resistance and/or inappropriate insulin secretion. However, even in T1D, in the dysregulation of immune system function, $\beta$-cell toxicity is mediated by a complex interplay between oxidative stress and inflammation, for which exercise could be protective. Recent studies have suggested that physical exercise may interfere with immune system function even at low intensity and duration.

Although current guidelines are robust and straightforward in recommending doses of exercise (types, duration, intensity) for subjects with T2D, a complex and multifactorial strategy has been outlined for the exerciserecommendations in $\mathrm{T} 1 \mathrm{D}$ with a large and uncertain therapeutic range of efficacy (due to difficult glycemic control, and adherence). This advocates for a personalized, omni-comprehensive approach to fully exploit the exercisebenefits in people with T1D.

\subsection{Immunomodulatory indications from animal and human models}

The nonobese diabetic (NOD) mouse has been studied as the elective model to mimic the diabetes progression in humans as it is characterized by progressive autoimmune destruction of pancreatic $\beta$-cells. We underwent NOD mice to a 12-week program of moderate-intensity treadmill training 
to investigate immunological and inflammatory modifications during T1D progression [2]. We ascertained glucose-lowering effects induced by exercise in the late states of diabetes, whereas control untrained NOD mice revealed the presence of larger infiltrates at the end of the study. These results suggested that exercise may exert a positive immunomodulation of systemic functions to both T1D and inflammation.

Within a unifying continuum of diabetes, we gathered a putative immunomodulatory effect of exercise in patients with T1D. According to our epidemiological screening, physical exercise would be able to prolong the "honeymoon", i.e. the period of time, in early pathogenesis of T1D, characterized by reduced need for exogenous insulin. We have seen honeymoon to be definitively longer in active people, like athletes with T1D. Specifically, we found a putative inverse relationship between autoimmunity markers (GAD, IA) and exercise-derived energy expenditure $[3,4]$.

In other longitudinal studies (observational and intervention) we showed that exercise may positively modulate immune system function in $\beta$-cells transplanted recipients. Active subjects with T1D, following islet transplantation (IT), exhibited ameliorated scores of disease management, quality of life [5], metabolic control, body composition [6]. In addition, in IT subjects, physical exercise was capable to counteract diabetic symptoms and mitigated the side effects of immunosuppressive drugs and graft dysfunction [7, 8]. After IT, in fact, progressive insulin resistance might arise as a result of immunosuppression and chronic inflammation. 
Literature reports several data supporting a complex interplay between immunological and metabolic scenarios. Fischer et al. demonstrated the involvement of interleukin-6 (IL-6) in the modulation of the immunological and metabolic responses to high-intensity exercise [9]. Ellingsgaard et al. documented positive effects of IL-6 on glucagon- [10] and insulin secretion through the action on glucagon-like peptide-1 (GLP-1) secretion, release, and subsequent $\beta$-cell signaling [11]. Da Silva Krause et al. confirmed that IL-6 promotes insulin secretion from clonal $\beta$-cells and pancreatic islets as this cytokine may exert GLP1-independent effects in the islet in vivo [12].

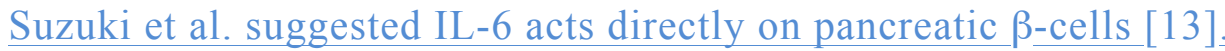
Altogether these IL-6 exercise-induced effects may restore the imbalance in the Th1/Th2 cytokines ratio observed in $\mathrm{T} 1 \mathrm{D}$, protecting from the autoimmune process directed to $\beta$-cells. We hypothesize that a direct exercise-intervention study would be capable to gain a greater effect on the immunological stand-point, as shown in previous studies.

\section{Exercise in T1D: the risk-benefit analysis}

Physical activity, sports and exercise should be encouraged in people with T1D for similar reasons it should be encouraged in people with T2D, or in the general population. Overall, regular exercise can decrease risk factors for cardiovascular diseases (CVD), it offers protection against all-cause mortality [4] and it may even improve quality of life in many individuals, under a variety of conditions [14]. Likewise for individuals with T2D, physical activity should be embodied in the management of T1D as it increases insulin sensitivity (both short and long term), lowers blood glucose levels, reduces body fat (and ameliorates body mass 
composition [6]), improves cardiovascular function. However, due to the loss of the $\beta$-cell pancreatic mass and/or -function, subjects with T1D uniquely face a number of challenges in preparation for, during, and after each session of exercise. While the metabolic control is typically achievable in T2D as adaptive response to exercise, a successful management of blood glucose is instead uncertain in T1D. If insulin levels are excessive, hypoglycemia may arise during and after exercise. On the contrary, if insulin levels are deficient, exercise may lead to hyperglycemia or ketosis. Appropriate approaches, combining adjusted insulin therapy and diet, may accommodate daily exercise. However, an individualized risk-benefit analysis must be run when prescribing an exercise program for people with T1D.

Strategies should be developed to minimize the risk of hypoglycemia the most frequent event during/after exercise, given the derangements in fuel metabolism of individuals with T1D. Research in the area of exercise and diabetes has shown the importance of tight glucose control as a pillar in the management of T1D, especially under physical activity stimulation. Relevant precautions may include reduced doses of insulin in anticipation of exercise [15]; ingestion of readily absorbable carbohydrates [16]; adjustment of basal insulin infusion in pump therapy [17] (Figure 1). In fact, the insulin pump therapy, allowing a continuous subcutaneous insulin infusion (CSII), represents one of the most cost-effective approaches in different populations with T1D. Integrated monitoring systems, comprising CSII and continuous glucose monitoring (CGM), have been proved to be efficient in exploiting the beneficial effects of exercise within a comprehensive T1D-based educational approach.

\section{Abnormal endocrine responses to exercise in T1D}


In healthy metabolism, glucose homeostasis is ensured during exercise through an array of neuroendocrine responses involving the growth hormone, cortisol, insulin, glucagon, and epinephrine. In other words, these responses modulate the balancing between glucose production and glucose utilization, during exercise, in order to maintain euglycemia (Figure 2). Unfortunately, these counter-regulatory responses may be abnormal or lost in T1D, and hypoglycemia arises as a frequent event among T1D-metabolic complications. In the early phase of the disease, usually before the onset of autonomic neuropathy, the sympathoadrenal responses are adequate to counteract hypoglycemia. However this defense can also be attenuated in later stages of T1D, and the consequent derangements, combined together, further increase the likelihood of hypoglycemia (hence, "hypoglycemia begets hypoglycemia”). Frequent hypoglycemia has been shown to reduce the glycemic threshold for activation of the counter-regulatory response needed to restore euglycemia during a subsequent hypoglycemic episode. As a result, some individuals develop hypoglycemia-associated autonomic failure (HAAF) and do not experience and respond to the potentially life-saving warning symptoms, therefore they are at increased risk of seizures, coma and death $[18,19]$. Nevertheless, some recent studies found that in T1D, exercise and hypoglycemia may have mutual blunting effect to their counter-regulatory responses $[20,21]$.

To summarize, blood glucose response to exercise is determined by a balance between hepatic glucose output and muscle glucose uptake; this balance is a function of diet, therapy, parameters related to exercise modality, and characteristics of the subjects.

\subsection{Exercise metabolism in health}


During exercise, due to the increased metabolism, blood glucose is rapidly exhausted . However, there are physiological mechanisms helping to maintain euglycemic levels. Key metabolic pathways interact to regulate the rate of glucose metabolism and to direct cellular bioenergetics toward a defined homeostasis. These mechanisms include:

1. Mobilization of glucose from liver glycogen stores;

2. Mobilization of non-esterified fatty acid (NEFA) from adipose tissue (which spares blood glucose);

3. Gluconeogenesis from the non-carbohydrate precursor such as amino acids, lactic acid, and glycerol;

4. Blocking the entry of glucose into cells and forcing the cells to use NEFA as a fuel.

\subsection{Exercise dys-metabolism in T1D}

Glycolysis - Pyruvate and lactate concentration. Intense short-term exercise induces glycogen breakdown to provide the substrate for activating anaerobic glycolysis and to assure constant energy supply. However, the process results in accumulation of plasma pyruvate and lactate. Many studies have confirmed an increased concentration of serum lactate and pyruvate after exercise. Unfortunately, in T1D the pyruvate response is found to be blunted [22]. Given that insulin inhibits glycogen breakdown, the presence of increased insulin levels in T1D may result in a reduced glycogenolytic response [23].

Fat metabolism. During exercise, when the energy supply does not match the demand, a low plasma glucose level can occur. As a result, catecholamines are released to stimulate lipolysis. This process, which involves reduction of 
triglycerides to free fatty acids, is catalyzed by lipase, and it is activated through the action of cortisol, epinephrine, norepinephrine, and growth hormone (GH). In response to exercise, healthy individuals show an increase in levels of free fatty acids and glycerol, as end-products of lipolysis [22, 24]. In T1D individuals, exercise-induced lipolysis is attenuated, again attributable to high insulin levels [23].

Protein metabolism. During exercise, when glucose is not available as the primary fuel, protein breakdown serves to provide an alternative source of energy. Studies indicate that high circulating insulin level in T1D may attenuate the process of protein breakdown. This is evidenced by lower levels of leucine, a product of protein breakdown [23].

Insulin response. Serum insulin levels in T1D patients are found to be high after 30 minutes of exercise. This increase in insulin could be one of the reasons for the diminished endocrine- and metabolic response to exercise in T1D [23]. Earlier, a study conducted to understand the exercise-induced lipolysis found increased levels of liposoluble vitamins in the blood stream, released from the subcutaneous fat tissue $[24,25]$. This observation implies that the insulin stored in the subcutaneous tissue may be gradually released in response to exercise due to lipolysis. High levels of insulin may reach supra-physiological levels, leading to insulin resistance in T1D $[26,27]$. In addition, studies have also found impaired glucose utilization and impaired insulin-induced NEFA suppression in T1D $[28,29]$. Insulin resistance is also evidenced in hepatic and skeletal muscle tissue, despite good glycemic control in T1D [30]. A study conducted on T1D adolescents revealed impaired functional exercise capacity and decreased insulin sensitivity [31]. However, these individuals had paradoxically normal 
intramyocellular lipid content (IMCL) which challenges the previous finding that IMCL accumulation a marker for insulin resistance in both T1D and T2D [32, 33].

\subsection{Hypoglycemia and delayed glucose recovery}

T1D patients are at high risk of hypoglycemia following exercise; in addition, there is delayed glucose recovery from hypoglycemia attributable to blunted glucagon response, reduced adrenomedullary response, and diminished clearance of injected insulin. In healthy people, the pancreas secretes glucagon in response to hypoglycemia. Glucagon stimulates the breakdown of glycogen in the liver (hepatic glycogenolysis). As a result, the glycogen is converted to glucose, thereby normalizing plasma glucose levels. Many studies have proved the fact that plasma glucagon response to hypoglycemia is markedly attenuated in diabetes. In long-standing T1D, this glucagon response is irreversibly lost [34, 35]. As a result, the body relies on other counterregulatory responses and takes a longer time to normalize the hypoglycemia induced by exercise.

Hypoglycemia is a potent stimulator of epinephrine. In response to hypoglycemia, the adrenal medulla secretes epinephrine which helps to counterregulate low glucose levels by promoting glycogenolysis and lipolysis. However, it has been found that in T1D patients, the plasma epinephrine levels are one third of their healthy counterparts, implying a blunted adrenomedullary response [36]. A very crucial factor in glucose recovery from hypoglycemia is the clearance of injected insulin. Research indicates that T1D patients have diminished clearance of injected insulin as evidenced by the prolonged initial half-time of disappearance of injected insulin [36]. It implies that T1D patients develop insulin resistance over time, which interferes with glucose uptake and their 
utilization by the tissues. Another important consideration is the body's dependability on the type of counterregulatory response to hypoglycemia. Studies have reported that recovery from insulin-induced hypoglycemia is unaffected by adrenergic blockade in healthy controls [37]. It indicates that adrenomedullary response (epinephrine secretion) is not critical to glucose recovery from hypoglycemia unless glucagon response is absent or reduced [34, 37]. It implies that T1D patients, with blunted or absent glucagon response, are dependent on epinephrine-mediated response for glucose recovery from hypoglycemia. This has been confirmed in studies that showed lower mean blood glucose levels, with smaller increments in mean plasma glucagon, in T1D patients when compared to their healthy counterparts $[38,39]$.

Exercise-induced hypoglycemia. In healthy people, the insulin levels drop during exercise, which stimulates the secretion of glucagon and promotes glycogenolysis. In T1D, the exogenous insulin levels do not drop, increasing the risk of exerciseinduced hypoglycemia [39-41].

There could be several possible reasons for the body's inability to reduce insulin levels. Firstly, the exercise is usually performed in a $0-4$-h period following an insulin injection. As a result, the insulin levels might not decrease due to the inadequate timeframe, and, furthermore, due to the pharmacokinetics of the insulin and time of its peak action [15]. Secondly, the injected insulin may get absorbed rapidly form the subcutaneous tissue, following exercise, resulting in increased insulin levels [42]. The increased levels of insulin promote peripheral uptake and utilization of glucose, aggravating the hypoglycemic state, complicated by limited glucagon response [43]. Thirdly, T1D patients have an attenuated glucagon response to hypoglycemia, decreasing the glycogen 
breakdown to glucose, which would have countered the hypoglycemia in healthy individuals $[37,38,44]$.

In some people with $\mathrm{T} 1 \mathrm{D}$, the glucagon response to exercise may be intact, in absence of hypoglycemia [44]. However, the glucagon response may be blunted if previously exposed to hypoglycemia [21]. Exercise-induced hypoglycemia may also be a result of blunted adrenomedullary responses to exercise in T1D [21]. T1D patients with poor glycemic control may have low hepatic glycogen content [45], again contributing to exercise-induced hypoglycemia.

Late glycemic excursions. Many patients with T1D experience exercise-induced late-onset hypoglycemia [18], about 7-11 hours post-exercise ("lag effect" of exercise) $[46,47]$. This might be harmful, especially because unaware: patients may unconsciously experience hypoglycemia during sleep. Physical activity during the daytime accelerate the risk of nocturnal hypoglycemia to about $30-40 \%$ [48-52]. This incidence resembles the need to accurately evaluate and identify the relative metabolic alterations occurring inside the body. Insulin sensitivity is pronounced in T1D immediately after exercise and again 7-11 hours later, increasing the risk for late glycemic excursions [46]. This implies the mandatory modification in the insulin therapy post exercise, especially the bedtime insulin [48].

\subsection{Exercise-induced hyperglycemia}

Decreased insulin levels in the portal circulation can result in hyperglycemia. In the absence of insulin, the muscle cells do not utilize glucose as fuel, and instead rely on fatty acids and ketones, leading to ketoacidosis. If the glycogenolysis from liver continues, without the muscles taking up glucose, the plasma glucose 
levels can shoot up, resulting in hyperglycemia [53]. Hyperglycemia can ensue following high-intensity exercise that increases cathecolamine and cortisol levels [54], augmenting, in turn, hepatic glucose production and limiting peripheral glucose disposal. In healthy individuals this increase in cathecolamines is compensated by for enhanced insulin secretion upon termination of exercise, whereas in T1D subjects such a phenomenon might exacerbate post-exercise hyperglycemia. However this hyperglycemic effect is transitory in diabetic subjects, lasting 1-2 hours in the recovery time $[55,56]$. Obviously, if a patient has hyperglycemia and presence of urinary ketones, exercise should be delayed $[57,58]$. Vigorous activity should be avoided especially with known insulin omission. Conversely, if elevated blood glucose is clearly attributable to underdosing insulin at the preceding meal, exercise may not be postponed based solely on hyperglycemia.

\subsection{Exercise types}

The physiological response to exercise depends upon the intensity, volume and frequency of exercises along with the muscle group involved. The rate of glycogen depletion is directly proportional to the intensity of exercise.

Glycogenolysis is rapid during high-intensity exercise. The process of glycogen breakdown is regulated by epinephrine levels. High-intensity exercise increases plasma epinephrine levels which in turn increase glycogen breakdown.

Some exercise types, such as aerobic exercise, even if performed for only $15 \mathrm{~min}$, cause a significant increase in plasma GH levels. The peak values are found at the end of the activity [59]. Other factors influencing the GH response to exercise include physical fitness, gender and age [59]. Studies show a linear dose- 
response between exercise intensity and GH secretion [60, 61]. Research studies have also found that sustained endurance training blunts the acute exerciseinduced GH release [62].

Anaerobic exercise involves intense muscular contraction resulting in accumulation of lactic acid. High lactate levels reduce the uptake and utilization of plasma glucose and NEFA in the skeletal muscle. It also promotes hepatic glucose production. These two mechanisms combined may result in hyperglycemia in T1D [63-65]. However, studies show that a 10-s high-intensity anaerobic sprint may help prevent early post-exercise hypoglycemia in T1D [66, 67]. Weight training before the onset of aerobic exercise has also been found to be helpful in maintaining the blood glucose levels in T1D [68].

As previously reported, intense aerobic exercise combined with equally intense anaerobic activity may increase blood glucose levels for $1-2 \mathrm{~h}$ in recovery [55, $56]$.

\subsubsection{High Intensity Intermittent Training: a possible new frontier of glucose control in} $T 1 D ?$

Intermittent high intensity exercise is a fascinating modality of training that consists in moderate intensity exercise with short bouts - repetitive sprinting - of interspersed all-out efforts. Few randomized controlled trials have investigated the beneficial effects of vigorous intensity exercise, specifically high intensity intermittent training, in adults with T1D. As mentioned, a single all-out sprint of $10 \mathrm{~s}$, upon completion of exercise, may counter the drop in glucose occurring post-exercise by activation of GLUT4. Conversely, the same $10 \mathrm{~s}$ burst executed before exercise did not impede the hypoglycemic event, although a stabilization of glycemic levels was achieved post-exercise. In fact, intermittent high-intensity 
exercise should be preferred over continuous moderate-intensity aerobic exercise to help prevent extreme excursion of glucose levels [69, 70]. Furthermore, intermittent high-intensity exercise decreases glucose disposal compared with continuous moderate intensity exercise, implying a high flexibility of the former type of exercise in shifting fuel metabolism towards consumption of alternatives substrates [71]. To conclude, intermittent high intensity exercise reduces metabolic destabilization post-effort; it offers protection against nocturnal hypoglycemia in athletes with T1D [70], and it has been also accompanied with enhanced muscle oxidative metabolism in young subjects with T1D [64]. International guidelines recommend to have participated at least in regular moderate-intensity exercise before performing short bursts of very intense activity interspersed with short period of recovery. Evidence for the efficacy of this training in obtaining stable glycemic control is lacking, however the optimal high-intensity intermittent training protocol has yet to be fully tested and determined.

\section{How to maximize exercise benefits in T1D}

Over the past decades a wide spectrum of scientific advances have been spanned through the diabetes management in order to greatly improve the psychological and behavioral burden of these patients. Options offered by technology and clinical care are various, ranging from frequent self-monitoring of blood glucose (SMBG) to islet-transplantation (IT). Use of blood glucose monitors is pivotal for controlling glycemic excursions in response to exercise: insulin and carbohydrate intake can be accordingly adjusted to prevent dysglycemic events (hyper-, or more often, hypo-glycemic episodes) throughout the day (Figure 3). A couple of glucose 
measurements prior to exercise, spaced 15-45 min apart, are recommended to identify patterns and trends. Ideally, blood glucose checks should be made every $30 \mathrm{~min}$ during physical activity so that strategies can be operated at the need. Even in the late recovery, glucose readings are important because of the increased insulin sensitivity occurring 7-11 hours post-exercise [46].

Continuous glucose monitoring (CGM) systems use a small sensor, inserted under the skin, that provides interstitial glucose readings as often as once per minute over a $24 \mathrm{~h}$ period. The sensor stays in place for several days up to a week, then it must be replaced. The measurements are transmitted to a wireless monitor, which allows gathering trends, particularly useful to reconstruct patterns modulated by exercise. However, real-time CGM tends to overestimate blood glucose levels in the low range, due to the $10-20$ min lag time between interstitial fluid and capillary glucose. This is notably alarming if hypoglycemia is developing, although short-term use of CGM with alarms has been shown to reduce the incidence and duration of hypoglycemia to a certain extent [72]. In another study [73], CGM revealed to be accurate despite markedly different metabolic and exercise conditions (high-intensity intermittent exercise versus continuous moderate). The coupling of CGM with insulin pump (continuous subcutaneous insulin infusion, CSII) has been proved to be efficient in gaining the beneficial effects of exercise in the management of T1D [6]. The CSII is a (relatively recent) technological breakthrough in the T1D therapy, as it allows to simulate the physiologic pancreatic secretion of insulin by delivering rapidacting insulin analogs throughout the day. With respect to multiple daily insulin injections (MDII), CSII offers a larger flexibility and a more accurate insulin administration so much as for tiny doses: both bolus insulin and the basal infusion rates can be adjusted by the users before, during, and after exercise. CSII is 
definitively advantageous as the basal insulin reduction following exercise can occur automatically during sleep, so to help prevent nocturnal hypoglycemia [48].

Furthermore, the introduction of new ultra-long acting basal insulins (insulin degludec, insulin glargine U-300) may substantially reduce dosing frequency because of their ultralong action profile (lasting $>24 \mathrm{~h}$ and possibly up to $40 \mathrm{~h}$ ), resulting in improved mental well-being scores [74] and, ultimately, in a drecreased incidence of hypoglycemia compared to their rival basal insulin analogs [75]. However, whether these new insulins may be efficacious, in relation to the exercise timing, remains to be elucidated.

Although the risks of hypoglycemic events cannot be totally excluded even under the strict control operated by CSII plus CGM, this latter combination represents one of the most promising automated model toward the pathway to the artificial pancreas.

Apart from closed-loop control systems or artificial pancreas, islet transplantation (IT) has become a desirable scenario, whenever possible, on numerous scientific and clinical fronts in the therapy and management of T1D [76]. IT restores glycemic control awareness and offers protection against severe hypoglycemia, at least in the mid-term after trasplant [77]. As to the exercise benefits, $\beta$-cells transplanted recipients have tremendously improved their medical outcome and lifestyle factors (i.e. insulin-independence, above all) even under conditions of ultraendurance training $[8,78]$.

With all these technological advances, at the other end of the spectrum, there is actually a quite bit of evidence that adequate lifestyle education and training to all people with T1D are still poor. Few parallel studies have investigated the rates of diabetes education in exercise, and T1D patients have harsh access to certified 
programs on diabetes self-management training, especially outside of major urban areas. Optimal diabetes control will certainly be achieved thanks to breakthrough technologies; however, at the simpler level, much more can yet be done on dissemination of adequate lifestyle education and adherence to treatment recommendations. This is also true when it comes to to exercise benefits in T1D.

\section{Aerobic exercise in T1D}

When glycemic control is not deteriorated in individuals with T1D, endurance training will likely induce the same adaptions to which healthy subjects normally respond to. Therefore aerobic training improves insulin sensitivity, blood lipid profile, physical fitness; increases energy expenditure; decreases blood pressure, risk of CVD; enhances psychological well-being. These adaptations are still appreciable even though glycemic control is not improved. Ultimately, long-term health and life expectancy will be favorably impacted by regular aerobic exercise even under conditions of impaired glycemic control. For these reasons, in the management of T1D, the goal of optimal blood glucose control is of paramount relevance. However, a decent glycemic control permits to achieve an elite level of sport performance. In a long-distance runner, $\beta$-cells transplanted, a high volume of aerobic training not only was compatible with the treatment of T1D, but also it counteracted diabetic symptoms and mitigated the side effects of immunosuppressive drugs and graft dysfunction over a 10 -year observation $[8,78]$. In a study on 10 triathletes with T1D, endurance performance was unaffected over 3 years, despite typical glycemic dysregulation through the race [79]. A normal cardiopulmonary peak was reported in adults with long-standing T1D, in a good glycemic control. 
T1D adolescents have shown to have an aerobic capacity $20 \%$ lower than peer-matched healthy controls [80]. A reduced maximal aerobic capacity has been reported in young patients with T1D with respect to their non-diabetic peers. Physical work capacity seems to be related to the level of glycemic control, which in turn explains, to some extent, athletic and sport skill performance. It is still uncertain whether reduced work capacity in young subjects with T1D results from poor oxygenation [81], low muscular capillarization [82], or if poor metabolic control depends on low regular physical activity [83].

According to the "American Diabetes Association" position statement [84, 85], children and adults should perform at least 60 min or more of moderate-tovigorous intensity, daily. Adults should be recommended to exercise at least 150 min/week for 3-7 days per week (with no more than 2 consecutive days of rest) at moderate-to-vigorous intensity (50-70\% of maximum heart rate; $50-85 \%$ of $\mathrm{VO}_{2} \max$ ). Adults able to run at about $10 \mathrm{~km} / \mathrm{h}$ may diminish the aforementioned duration, by running $75 \mathrm{~min} /$ week (subjectively "vigorously") on at least 25 -min block.

\section{Resistance exercise in T1D}

Resistance exercises are based on the use of muscular strength to move a weight or work against a resistant load to a maximal extent (strength, force) or repeatedly (muscle endurance). Such training not only improves musculoskeletal health but it helps to maintain independence in carrying out daily activities, with reduced risk of injuries.

Muscular mass and strength can be positively enhanced by resistance training in individuals with T1D. The effects of resistance exercise on glycemic control in T1D are still controversial, not univocally ascertained, but promising. For 
instance, resistance training has been shown to be effective in minimizing risk of hypoglycemia post-exercise in T1D [86]. Prior to neuropathic complications, skeletal muscle abnormalities have been observed in T1D patients, suggesting the existence of a typical diabetic myopathy in humans [83]. Decrements in musculo-skeletal strength, loss in muscle fiber size, and increase in glycolytic enzymes and fast-twitch fibers have been reported in individuals with T1D. Others have shown slower conduction velocity and motor unit discharge frequency during muscular isometric contractions in T1D [87]. These factors, along with higher glycolytic flux (e.g. muscle glycogen as preferred energy source), early dehydration and acidosis [88], might promote early fatigue in these T1D populations (both pediatric- and adult-).

Hence, appropriately orchestrated resistance training programs may counteract this mass remodeling detrimental for the metabolism of T1D subjects. Types of resistance training may include weight lifting (free weights), specific isotonic machines, bands, isometric exercises and calisthenics.

“American Diabetes Association" recommends adults to perform moderate (15 repetitions at maximum effort) to vigorous (repetitions at maximum effort) resistance activities, 2-3 days/week on non-consecutive days. At least 8-10 exercises with completion of 1-3 sets of 10-15 repetitions near to fatigue per set [85]. Conditioning of the body core and balance training (time standing on a definite position) are as well envisaged. Children and youth should incorporate such muscleconditioning activities as part of their daily play, games, recreation, physical education, family context. Importantly, these activities should exceed the sedentary time, by accumulating planned and structured physical effort in the course of daily living. 
Whatever the primary goal of the training will be, either improvements in functional capacity or increased ability to care for oneself, the resistance program should anyway consider the possible presence of chronic comorbidities typical of the disease (neuropathy, vascular damage, CVD). Such health concerns ought to be medically addressed before engaging in resistance training.

\section{Exercise defense against syndromic inflammation in diabetes}

Several studies documented elevated circulating inflammatory and oxidative stress markers in patients with T1D. On a side, oxidative stress may be seen as a characteristic trait of T1D, on the other one, hyperglycemia can exacerbate this scenario of systemic inflammation. T1D patients exhibit numerous features of atherogenesis, including activation of transcription factors stimulating expression of proinflammatory cytokines. In reality, a vast array of conditions threatens the functionality of the $\beta$-pancreatic mass, promoting islet inflammation and metabolic stress/imbalance. It is possible that increased stimulation of the $\beta$-cells due to overfeeding, obesity, insulin resistance, psychological stress, infections, and low physical activity, stimulate or sometimes even initiate the autoimmune attack leading the insulin-producing islet-cells to the their failure. Exercise triggers a cytokine response that may be anti-inflammatory and offers protection to $\beta$-cell against all these insults.

Depending on intensity, type and duration, physical exercise is a potent modulator of physiological changes at different levels, pertaining stress hormones, energy crisis and oxidative stress. Regularly exercising at moderate intensity has been shown to enhance the antioxidant defense system, thus reducing the oxidative stress. To a variable degree, as already observed in other chronic 
inflammatory conditions, these exercise-related adaptations may express a favorable cytokine pattern and may preserve the $\beta$-cell redox homeostasis - and thus its insulin secreting capacity - against the multiple-origin attacks directed towards $\beta$-cells. However, inconclusive data have been reported on exercise-induced cytokine response (TNF- $\alpha$, IL6) with a putative beneficial health effect. According to our observations, physical exercise may be helping in two way by both enhancing insulin sensitivity (increasing insulin action) and $\beta$-cell function through the reduction of the deleterious effects of autoimmunity. These two effects are likely to combine together and produce a substantial gain in glucose tolerance [4].

\section{Integrative view}

Multiple improvements in health indicators firmly remark that regular exercise is essential in the management and lifestyle of people with T1D (Table 2). Nevertheless, given the endocrine responses to exercise in T1D are blunted and inadequate, clinicians and exercise professionals must allow discretion when prescribing physical activity. Exercise programs should be meticulously based on close monitoring of physical activity and the body's response in terms of glycemic fluctuations and inflammatory or oxidative parameters. 


\section{Statement of Human and Animal Rights}

This article does not contain any studies involving human or animal subjctes performed by any of the authors.

\section{Conflict of Interest}

The authors declare that they have no conflict of interest.

\section{Contribution statement}

All authors were responsible for drafting the manuscript and revising it critically for valuable intellectual content. All authors approved the version to be published.

\section{Acknowledgements}

The authors would like to thank Michela Adamo for having reviewed the manuscript thoroughly.

\section{Funding}

This research did not receive any specific grant from funding agencies in the public, commercial, or not-for-profit sectors. 


\section{References}

1. Kahn SE, Prigeon RL, McCulloch DK, et al (1993) Quantification of the Relationship Between Insulin Sensitivity and $\beta$-Cell Function in Human Subjects: Evidence for a Hyperbolic Function. Diabetes 42:

2. Codella R, Lanzoni G, Zoso A, et al Moderate Intensity Training Impact on the Inflammatory Status and Glycemic Profiles in NOD Mice. doi: $10.1155 / 2015 / 737586$

3. Luzi L, Codella R, Lauriola V, et al (2011) Immunomodulatory effects of exercise in type 1 diabetes mellitus. Diabetes 60:A209-A210.

4. Codella R, Luzi L, Inverardi L, Ricordi C (2015) The anti-inflammatory effects of exercise in the syndromic thread of diabetes and autoimmunity. Eur Rev Med Pharmacol Sci 19:3709-22.

5. Delmonte V, Peixoto EML, Poggioli R, et al (2013) Ten years' evaluation of diet, anthropometry, and physical exercise adherence after islet allotransplantation. Transplant Proc 45:2025-8. doi: 10.1016/j.transproceed.2013.01.031

6. Adamo M, Codella R, Casiraghi F, et al (2016) Active subjects with autoimmune type 1 diabetes have better metabolic profiles than sedentary controls. Cell Transplant (in press).

7. Delmonte V, Codella R, Piemonti L, et al (2014) Effects of exercise in a islettransplanted half-marathon runner: outcome on diabetes management, training and metabolic profile. Sport Sci Health 10:49-52. doi: 10.1007/s11332-0130164-7

8. Codella R, Adamo M, Maffi P, et al (2016) Ultra-marathon $100 \mathrm{~km}$ in an islettransplanted runner. Acta Diabetol 1-4. doi: 10.1007/s00592-016-0938-x

9. Fischer CP (2006) Interleukin-6 in acute exercise and training: what is the biological relevance? Exerc Immunol Rev 12:6-33.

10. Ellingsgaard H, Ehses JA, Hammar EB, et al (2008) Interleukin-6 regulates pancreatic alpha-cell mass expansion. Proc Natl Acad Sci U S A 105:13163-8. doi: 10.1073/pnas.0801059105

11. Ellingsgaard H, Hauselmann I, Schuler B, et al (2011) Interleukin-6 enhances insulin secretion by increasing glucagon-like peptide-1 secretion from L cells and alpha cells. Nat Med 17:1481-9. doi: 10.1038/nm.2513 
12. da Silva Krause M, Bittencourt A, Homem de Bittencourt PI, et al (2012) Physiological concentrations of interleukin-6 directly promote insulin secretion, signal transduction, nitric oxide release, and redox status in a clonal pancreatic $\beta$-cell line and mouse islets. J Endocrinol 214:301-11. doi: 10.1530/JOE-120223

13. Suzuki T, Imai J, Yamada T, et al (2011) Interleukin-6 enhances glucosestimulated insulin secretion from pancreatic beta-cells: potential involvement of the PLC-IP3-dependent pathway. Diabetes 60:537-47. doi: 10.2337/db100796

14. Codella R, Terruzzi I, Luzi L (2016) Sugars, exercise and health. J Affect Disord. doi: 10.1016/j.jad.2016.10.035

15. Rabasa-Lhoret R, Bourque J, Ducros F, Chiasson JL (2001) Guidelines for premeal insulin dose reduction for postprandial exercise of different intensities and durations in type 1 diabetic subjects treated intensively with a basal-bolus insulin regimen (ultralente-lispro). Diabetes Care 24:625-630. doi: 10.2337/diacare.24.4.625

16. Dubé MC, Weisnagel SJ, Prud'homme D, Lavoie C (2005) Exercise and newer insulins: How much glucose supplement to avoid hypoglycemia? Med Sci Sports Exerc 37:1276-1282. doi: 10.1249/01.mss.0000174950.25188.36

17. Yardley JE, Iscoe KE, Sigal RJ, et al (2013) Insulin pump therapy is associated with less post-exercise hyperglycemia than multiple daily injections: an observational study of physically active type 1 diabetes patients. Diabetes Technol Ther. doi: 10.1089/dia.2012.0168

18. Cryer PE (2010) Hypoglycemia in type 1 diabetes mellitus. Endocrinol Metab Clin North Am 39:641-654. doi: 10.1016/j.ecl.2010.05.003

19. Cryer PE (2008) The barrier of hypoglycemia in diabetes. Diabetes 57:31693176. doi: $10.2337 / \mathrm{db} 08-1084$

20. Davis SN, Mann S, Galassetti P, et al (2000) Effects of differing durations of antecedent hypoglycemia on counterregulatory responses to subsequent hypoglycemia in normal humans. Diabetes 49:1897-1903. doi: 10.2337/diabetes.49.11.1897

21. Galassetti P, Tate D, Neill RA, et al (2003) Effect of antecedent hypoglycemia on counterregulatory responses to subsequent euglycemic exercise in type 1 diabetes. Diabetes 52:1761-1769. doi: 10.2337/diabetes.52.7.1761 
22. Lewis GD, Farrell L, Wood MJ, et al (2010) Metabolic signatures of exercise in human plasma. Sci Transl Med 2:33ra37. doi: 10.1126/scitranslmed.3001006

23. Brugnara L, Vinaixa M, Murillo S, et al (2012) Metabolomics approach for analyzing the effects of exercise in subjects with type 1 diabetes mellitus. PLoS One. doi: 10.1371/journal.pone.0040600

24. Chatzinikolaou A, Fatouros I, Petridou A, et al (2008) Adipose tissue lipolysis is upregulated in lean and obese men during acute resistance exercise. Diabetes Care 31:1397-1399. doi: 10.2337/dc08-0072

25. Davison GW, George L, Jackson SK, et al (2002) Exercise, free radicals, and lipid peroxidation in type 1 diabetes mellitus. Free Radic Biol Med 33:15431551.

26. Jia G, DeMarco VG, Sowers JR (2015) Insulin resistance and hyperinsulinaemia in diabetic cardiomyopathy. Nat Rev Endocrinol 12:144153. doi: $10.1038 /$ nrendo.2015.216

27. Kaul K, Apostolopoulou M, Roden M (2015) Insulin resistance in type 1 diabetes mellitus. Metabolism 64:1629-1639. doi:

10.1016/j.metabol.2015.09.002

28. Schauer IE, Snell-Bergeon JK, Bergman BC, et al (2011) Insulin resistance, defective insulin-mediated fatty acid suppression, and coronary artery calcification in subjects with and without type 1 diabetes: The CACTI study. Diabetes 60:306-14. doi: 10.2337/db10-0328

29. Caprio S, Amiel S, Tamborlane W V, et al (1990) Defective free-fatty acid and oxidative glucose metabolism in IDDM during hypoglycemia. Influence of glycemic control. Diabetes 39:134-41.

30. Bergman BC, Howard D, Schauer IE, et al (2012) Features of hepatic and skeletal muscle insulin resistance unique to type 1 diabetes. J Clin Endocrinol Metab 97:1663-1672. doi: 10.1210/jc.2011-3172

31. Nadeau KJ, Regensteiner JG, Bauer TA, et al (2010) Insulin resistance in adolescents with type 1 diabetes and its relationship to cardiovascular function. J Clin Endocrinol Metab 95:513-521. doi: 10.1210/jc.2009-1756; 10.1210/jc. $2009-1756$

32. Perseghin G, Lattuada G, Danna M, et al (2003) Insulin resistance, intramyocellular lipid content, and plasma adiponectin in patients with type 1 diabetes. Am J Physiol Endocrinol Metab 285:E1174-E1181. doi: 
10.1152/ajpendo.00279.2003

33. Levin K, Daa Schroeder H, Alford FP, Beck-Nielsen H (2001) Morphometric documentation of abnormal intramyocellular fat storage and reduced glycogen in obese patients with Type II diabetes. Diabetologia 44:824-833. doi:

$10.1007 / \mathrm{s} 001250100545$

34. Caprio S, Napoli R, Saccà L, et al (1992) Impaired stimulation of gluconeogenesis during prolonged hypoglycemia in intensively treated insulindependent diabetic subjects. J Clin Endocrinol Metab 75:1076-1080. doi: 10.1210/jcem.75.4.1400874

35. Siafarikas A, Johnston RJ, Bulsara MK, et al (2012) Early Loss of the Glucagon Response to Hypoglycemia in Adolescents With Type 1 Diabetes. Diabetes Care 35:1757-1762. doi: 10.2337/dc11-2010

36. Popp DA, Shah SD, Cryer PE (1982) Role of epinephrine-mediated betaadrenergic mechanisms in hypoglycemic glucose counterregulation and posthypoglycemic hyperglycemia in insulin-dependent diabetes mellitus. J Clin Invest 69:315-26. doi: 10.1172/jci110455

37. Hoffman RP (2007) Sympathetic mechanisms of hypoglycemic counterregulation. Curr Diabetes Rev 3:185-93.

38. Tesfaye N, Seaquist ER (2010) Neuroendocrine responses to hypoglycemia. Ann N Y Acad Sci 1212:12-28. doi: 10.1111/j.1749-6632.2010.05820.x

39. Sprague JE, Arbeláez AM (2011) Glucose counterregulatory responses to hypoglycemia. Pediatr Endocrinol Rev 9:463-73; quiz 474-5.

40. Wasserman DH (2008) Berson Award Lecture 2008 Four Grams of Glucose. Am. J. Physiol. Endocrinol. Metab.

41. Camacho RC, Galassetti P, Davis SN, Wasserman DH (2005) Glucoregulation during and after exercise in health and insulin-dependent diabetes. Exerc Sport Sci Rev 33:17-23.

42. Mallad A, Hinshaw L, Schiavon M, et al (2015) Exercise effects on postprandial glucose metabolism in type 1 diabetes: a triple-tracer approach. Am J Physiol Endocrinol Metab 308:E1106-15. doi: 10.1152/ajpendo.00014.2015

43. Chokkalingam K, Tsintzas K, Snaar JEM, et al (2007) Hyperinsulinaemia during exercise does not suppress hepatic glycogen concentrations in patients with type 1 diabetes: a magnetic resonance spectroscopy study. Diabetologia 
50:1921-1929. doi: 10.1007/s00125-007-0747-4

44. Schneider SH, Vitug A, Ananthakrishnan R, Khachadurian AK (1991) Impaired adrenergic response to prolonged exercise in type I diabetes. Metabolism 40:1219-1225. doi: 10.1016/0026-0495(91)90219-M

45. Kacerovsky M, Jones J, Schmid AI, et al (2011) Postprandial and fasting hepatic glucose fluxes in long-standing type 1 diabetes. Diabetes 60:1752-8. doi: $10.2337 / \mathrm{db} 10-1001$

46. McMahon SK, Ferreira LD, Ratnam N, et al (2007) Glucose requirements to maintain euglycemia after moderate-intensity afternoon exercise in adolescents with type 1 diabetes are increased in a biphasic manner. J Clin Endocrinol Metab 92:963-8. doi: 10.1210/jc.2006-2263

47. The Diabetes Research in Children E, Mauras N, Beck RW, et al (2005) Impact of Exercise on Overnight Glycemic Control in Children with Type 1 Diabetes Mellitus. J Pediatr 147:528-534. doi: 10.1016/j.jpeds.2005.04.065

48. Taplin CE, Cobry E, Messer L, et al (2010) Preventing Post-Exercise Nocturnal Hypoglycemia in Children with Type 1 Diabetes. J Pediatr 157:784-788.e1. doi: $10.1016 /$ j.jpeds.2010.06.004

49. Iscoe KE, Corcoran M, Riddell MC (2008) High Rates of Nocturnal Hypoglycemia in a Unique Sports Camp for Athletes with Type 1 Diabetes: Lessons Learned from Continuous Glucose Monitoring Systems. Can J Diabetes 32:182-189. doi: 10.1016/S1499-2671(08)23008-X

50. Iscoe KE, Campbell JE, Jamnik V, et al (2006) Efficacy of Continuous RealTime Blood Glucose Monitoring During and After Prolonged High-Intensity Cycling Exercise: Spinning with a Continuous Glucose Monitoring System. Diabetes Technol Ther 8:627-635. doi: 10.1089/dia.2006.8.627

51. The DR in CNSG (2005) Impact of exercise on overnight glycemic control in children with type 1 diabetes mellitus. J Pediatr 147:528-34. doi:

10.1016/j.jpeds.2005.04.065

52. Maran A, Pavan P, Bonsembiante B, et al (2010) Continuous Glucose Monitoring Reveals Delayed Nocturnal Hypoglycemia After Intermittent HighIntensity Exercise in Nontrained Patients with Type 1 Diabetes. Diabetes Technol Ther 12:763-768. doi: 10.1089/dia.2010.0038

53. American Diabetes Association (2014) Standards of Medical Care in Diabetes-2014. Diabetes Care 37:S14-S80. doi: 10.2337/dc14-S014 
54. Benedini S, Longo S, Caumo A, et al (2012) Metabolic and hormonal responses to a single session of kumite (free non-contact fight) and kata (highly ritualized fight) in karate athletes. Sport Sci Health 8:81-85. doi: $10.1007 / \mathrm{s} 11332-012-0132-7$

55. Delvecchio M, Zecchino C, Salzano G, et al (2009) Effects of moderate-severe exercise on blood glucose in Type 1 diabetic adolescents treated with insulin pump or glargine insulin. J Endocrinol Invest 32:519-24. doi: 10.1007/BF03346499

56. Marliss EB, Vranic M (2002) Intense exercise has unique effects on both insulin release and its roles in glucoregulation: Implications for diabetes. Diabetes. doi: 10.2337/diabetes.51.2007.S271

57. Robertson K, Adolfsson P, Scheiner G, et al (2009) Exercise in children and adolescents with diabetes. Pediatr Diabetes 10:154-168. doi: 10.1111/j.13995448.2009.00567.x

58. Riddell MC, Sigal RJ (2013) Physical activity, exercise and diabetes. Can J Diabetes 37:359-360. doi: 10.1016/j.jcjd.2013.10.001

59. Gibney J, Healy M-L, Sönksen PH (2007) The Growth Hormone/Insulin-Like Growth Factor-I Axis in Exercise and Sport. Endocr Rev 28:603-624. doi: 10.1210/er.2006-0052

60. Pritzlaff CJ, Wideman L, Blumer J, et al (2000) Catecholamine release, growth hormone secretion, and energy expenditure during exercise vs. recovery in men. J Appl Physiol 89:937-46.

61. Pritzlaff-Roy CJ, Widemen L, Weltman JY, et al (2002) Gender governs the relationship between exercise intensity and growth hormone release in young adults. J Appl Physiol 92:2053-60. doi: 10.1152/japplphysiol.01018.2001

62. Wideman L, Weltman JY, Hartman ML, et al (2002) Growth hormone release during acute and chronic aerobic and resistance exercise: recent findings. Sports Med 32:987-1004.

63. Brooks G a (2009) Cell-cell and intracellular lactate shuttles. J Physiol 587:5591-600. doi: 10.1113/jphysiol.2009.178350

64. Harmer AR, Chisholm DJ, McKenna MJ, et al (2008) Sprint Training Increases Muscle Oxidative Metabolism During High-Intensity Exercise in Patients With Type 1 Diabetes. Diabetes Care 31:2097-2102. doi: 10.2337/dc08-0329

65. Fahey AJ, Paramalingam N, Davey RJ, et al (2012) The Effect of a Short 
Sprint on Postexercise Whole-Body Glucose Production and Utilization Rates in Individuals with Type 1 Diabetes Mellitus. J Clin Endocrinol Metab 97:4193-4200. doi: 10.1210/jc.2012-1604

66. Bussau VA, Ferreira LD, Jones TW, Fournier PA (2006) The 10-s maximal sprint: a novel approach to counter an exercise-mediated fall in glycemia in individuals with type 1 diabetes. Diabetes Care 29:601-6.

67. Bussau VA, Ferreira LD, Jones TW, Fournier PA (2007) A 10-s sprint performed prior to moderate-intensity exercise prevents early post-exercise fall in glycaemia in individuals with type 1 diabetes. Diabetologia 50:1815-8. doi: $10.1007 / \mathrm{s} 00125-007-0727-8$

68. Yardley JE, Kenny GP, Perkins BA, et al (2012) Effects of Performing Resistance Exercise Before Versus After Aerobic Exercise on Glycemia in Type 1 Diabetes. Diabetes Care 35:669-675. doi: 10.2337/dc11-1844

69. Guelfi KJ, Ratnam N, Smythe GA, et al (2007) Effect of intermittent highintensity compared with continuous moderate exercise on glucose production and utilization in individuals with type 1 diabetes. Am J Physiol Endocrinol Metab 292:E865-70. doi: 10.1152/ajpendo.00533.2006

70. Iscoe KE, Riddell MC (2011) Continuous moderate-intensity exercise with or without intermittent high-intensity work: effects on acute and late glycaemia in athletes with Type 1 diabetes mellitus. Diabet Med 28:824-32. doi: 10.1111/j.1464-5491.2011.03274.x

71. Bally L, Zueger T, Buehler T, et al (2016) Metabolic and hormonal response to intermittent high-intensity and continuous moderate intensity exercise in individuals with type 1 diabetes: a randomised crossover study. Diabetologia 59:776-784. doi: 10.1007/s00125-015-3854-7

72. Davey RJ, Jones TW, Fournier PA (2010) Effect of short-term use of a continuous glucose monitoring system with a real-time glucose display and a low glucose alarm on incidence and duration of hypoglycemia in a home setting in type 1 diabetes mellitus. J Diabetes Sci Technol 4:1457-64.

73. Bally L, Zueger T, Pasi N, et al (2016) Accuracy of continuous glucose monitoring during differing exercise conditions. Diabetes Res Clin Pract 112:1-5. doi: 10.1016/j.diabres.2015.11.012

74. Home PD, Meneghini L, Wendisch U, et al (2012) Improved health status with insulin degludec compared with insulin glargine in people with Type 1 
diabetes. Diabet Med 29:716-720. doi: 10.1111/j.1464-5491.2011.03547.x

75. NASRALLAH SN, NASRALLAH LR, L. Raymond Reynolds (2012) Insulin Degludec, The New Generation Basal Insulin or Just another Basal Insulin? Clin Med Insights Endocrinol Diabetes 5:31. doi: 10.4137/CMED.S9494

76. Pellegrini S, Cantarelli E, Sordi V, et al (2016) The state of the art of islet transplantation and cell therapy in type 1 diabetes. Acta Diabetol 53:683-691. doi: 10.1007/s00592-016-0847-z

77. Hering BJ, Clarke WR, Bridges ND, et al (2016) Phase 3 Trial of Transplantation of Human Islets in Type 1 Diabetes Complicated by Severe Hypoglycemia. Diabetes Care 39:1230-40. doi: 10.2337/dc15-1988

78. Delmonte V, Codella R, Piemonti L, et al (2014) Effects of exercise in a islettransplanted half-marathon runner: outcome on diabetes management, training and metabolic profile. Sport Sci Health. doi: 10.1007/s11332-013-0164-7

79. Boehncke S, Poettgen K, Maser-Gluth C, et al (2009) [Endurance capabilities of triathlon competitors with type 1 diabetes mellitus]. Dtsch Med Wochenschr 134:677-82. doi: 10.1055/s-0029-1208104

80. Komatsu WR, Gabbay MAL, Castro ML, et al (2005) Aerobic exercise capacity in normal adolescents and those with type 1 diabetes mellitus. Pediatr Diabetes 6:145-9. doi: 10.1111/j.1399-543X.2005.00120.x

81. Levy BI, Schiffrin EL, Mourad J-J, et al (2008) Impaired Tissue Perfusion. Circulation 118:

82. Kivelä R, Silvennoinen M, Touvra A-M, et al (2006) Effects of experimental type 1 diabetes and exercise training on angiogenic gene expression and capillarization in skeletal muscle. FASEB J 20:1570-2. doi: 10.1096/fj.054780fje

83. Krause MP, Riddell MC, Hawke TJ (2011) Effects of type 1 diabetes mellitus on skeletal muscle: Clinical observations and physiological mechanisms. Pediatr Diabetes 12:345-364. doi: 10.1111/j.1399-5448.2010.00699.x

84. Chiang JL, Kirkman MS, Laffel LMB, et al (2014) Type 1 Diabetes Through the Life Span: A Position Statement of the American Diabetes Association. Diabetes Care 37:2034-2054. doi: 10.2337/dc14-1140

85. Colberg SR, Sigal RJ, Yardley JE, et al (2016) Physical Activity/Exercise and Diabetes: A Position Statement of the American Diabetes Association.

Diabetes Care 39:2065-2079. doi: 10.2337/dc16-1728 
86. Yardley JE, Kenny GP, Perkins B a, et al (2013) Resistance versus aerobic exercise: acute effects on glycemia in type 1 diabetes. Diabetes Care 36:537-42. doi: $10.2337 / \mathrm{dc} 12-0963$

87. Almeida S, Riddell MC, Cafarelli E (2008) Slower conduction velocity and motor unit discharge frequency are associated with muscle fatigue during isometric exercise in type 1 diabetes mellitus. Muscle Nerve 37:231-40. doi: 10.1002/mus.20919

88. Magee MF, Bhatt BA (2001) Management of decompensated diabetes. Diabetic ketoacidosis and hyperglycemic hyperosmolar syndrome. Crit Care Clin 17:75-106.

89. Horton WB, Subauste JS (2016) Care of the Athlete With Type 1 Diabetes Mellitus: A Clinical Review. Int J Endocrinol Metab 14:e36091. doi: 10.5812/ijem.36091

90. Gallen IW, Hume C, Lumb A (2011) Fuelling the athlete with type 1 diabetes. Diabetes, Obes Metab 13:130-136. doi: 10.1111/j.1463-1326.2010.01319.x

91. Andersen H, Poulsen PL, Mogensen CE, Jakobsen J (1996) Isokinetic muscle strength in long-term IDDM patients in relation to diabetic complications. Diabetes 45:440-5.

92. Andreassen CS, Jakobsen J, Ringgaard S, et al (2009) Accelerated atrophy of lower leg and foot muscles--a follow-up study of long-term diabetic polyneuropathy using magnetic resonance imaging (MRI). Diabetologia 52:1182-91. doi: 10.1007/s00125-009-1320-0

93. Campbell MD, Walker M, Bracken RM, et al (2015) Insulin therapy and dietary adjustments to normalize glycemia and prevent nocturnal hypoglycemia after evening exercise in type 1 diabetes: a randomized controlled trial. BMJ Open Diabetes Res Care 3:e000085-e000085. doi: 10.1136/bmjdrc-2015000085

94. McAuley SA, Horsburgh JC, Ward GM, et al (2016) Insulin pump basal adjustment for exercise in type 1 diabetes: a randomised crossover study. Diabetologia. doi: 10.1007/s00125-016-3981-9

95. Sherr JL, Cengiz E, Palerm CC, et al (2013) Reduced hypoglycemia and increased time in target using closed-loop insulin delivery during nightswith or without antecedent afternoon exercise in type 1 diabetes. Diabetes Care. doi: $10.2337 / \mathrm{dc} 13-0010$ 
96. Martínez-Ramonde T, Alonso N, Cordido F, et al (2014) Importance of Exercise in the Control of Metabolic and Inflammatory Parameters at the Moment of Onset in Type 1 Diabetic Subjects. Exp Clin Endocrinol Diabetes 122:334-340. doi: 10.1055/s-0034-1372581

97. Davey RJ, Howe W, Paramalingam N, et al (2013) The Effect of Midday Moderate-Intensity Exercise on Postexercise Hypoglycemia Risk in Individuals With Type 1 Diabetes. J Clin Endocrinol Metab 98:2908-2914. doi: 10.1210/jc.2013-1169

98. Tunar M, Ozen S, Goksen D, et al (2012) The effects of Pilates on metabolic control and physical performance in adolescents with type 1 diabetes mellitus. $\mathrm{J}$ Diabetes Complications 26:348-351. doi: 10.1016/j.jdiacomp.2012.04.006

99. Yardley JE, Kenny GP, Perkins BA, et al (2015) Resistance Exercise in Already-Active Diabetic Individuals (READI): Study rationale, design and methods for a randomized controlled trial of resistance and aerobic exercise in type 1 diabetes. Contemp Clin Trials 41:129-138. doi: 10.1016/j.cct.2014.12.017

100. Shetty VB, Fournier PA, Davey RJ, et al (2016) Effect of exercise intensity on glucose requirements to maintain euglycemia during exercise in type 1 diabetes. J Clin Endocrinol Metab 101:972-980. doi: 10.1210/jc.2015-4026

101. Davey RJ, Bussau VA, Paramalingam N, et al (2013) A 10-s Sprint Performed After Moderate-Intensity Exercise Neither Increases nor Decreases the Glucose Requirement to Prevent Late-Onset Hypoglycemia in Individuals With Type 1 Diabetes. Diabetes Care 36:4163-4165. doi: 10.2337/dc12-2198

102. Komatsu WR, Barros Neto TL, Chacra AR, Dib S a (2010) Aerobic exercise capacity and pulmonary function in athletes with and without type 1 diabetes. Diabetes Care 33:2555-7. doi: 10.2337/dc10-0769

103. Veves A, Saouaf R, Donaghue VM, et al (1997) Aerobic exercise capacity remains normal despite impaired endothelial function in the micro- and macrocirculation of physically active IDDM patients. Diabetes 46:1846-52.

104. Gusso S, Hofman P, Lalande S, et al (2008) Impaired stroke volume and aerobic capacity in female adolescents with type 1 and type 2 diabetes mellitus. Diabetologia 51:1317-20. doi: 10.1007/s00125-008-1012-1

105. Salem MA, AboElAsrar MA, Elbarbary NS, et al (2010) Is exercise a therapeutic tool for improvement of cardiovascular risk factors in adolescents 
with type 1 diabetes mellitus? A randomised controlled trial. Diabetol Metab Syndr 2:47. doi: 10.1186/1758-5996-2-47

106. Herbst A, Kordonouri O, Schwab KO, et al (2007) Impact of physical activity on cardiovascular risk factors in children with type 1 diabetes: a multicenter study of 23,251 patients. Diabetes Care 30:2098-100. doi: 10.2337/dc06-2636

107. Huber J, Fröhlich-Reiterer EE, Sudi K, et al (2010) The influence of physical activity on ghrelin and IGF-1/IGFBP-3 levels in children and adolescents with type 1 diabetes mellitus. Pediatr Diabetes 11:383-5. doi: 10.1111/j.13995448.2009.00604.x

108. Laaksonen DE, Atalay M, Niskanen LK, et al (2000) Aerobic exercise and the lipid profile in type 1 diabetic men: a randomized controlled trial. Med Sci Sports Exerc 32:1541-8.

109. Dubé MC, Joanisse DR, Prud'homme D, et al (2006) Muscle adiposity and body fat distribution in type 1 and type 2 diabetes: varying relationships according to diabetes type. Int J Obes 30:1721-1728. doi: 10.1038/sj.ijo.0803337

110. Kennedy A, Nirantharakumar K, Chimen M, et al (2013) Does Exercise Improve Glycaemic Control in Type 1 Diabetes? A Systematic Review and Meta-Analysis. PLoS One. doi: 10.1371/journal.pone.0058861

111. Bohn B, Herbst A, Pfeifer M, et al (2015) Impact of Physical Activity on Glycemic Control and Prevalence of Cardiovascular Risk Factors in Adults With Type 1 Diabetes: A Cross-sectional Multicenter Study of 18,028 Patients. Diabetes Care 38:1536-43. doi: 10.2337/dc15-0030

112. Quirk H, Blake H, Tennyson R, et al (2014) Physical activity interventions in children and young people with Type 1 diabetes mellitus: a systematic review with meta-analysis. Diabet Med 31:1163-73. doi: 10.1111/dme.12531

113. Avogaro A, Gnudi L, Valerio A, et al (1993) Effects of different plasma glucose concentrations on lipolytic and ketogenic responsiveness to epinephrine in type I (insulin-dependent) diabetic subjects. J Clin Endocrinol Metab 76:845-850. doi: 10.1210/jcem.76.4.8473394

114. da Silva Krause M, de Bittencourt PIH (2008) Type 1 diabetes: can exercise impair the autoimmune event? TheL-arginine/glutamine coupling hypothesis. Cell Biochem Funct 26:406-433. doi: 10.1002/cbf.1470

115. Codella R, Luzi L, Inverardi L, Ricordi C (2015) The anti-inflammatory effects 
of exercise in the syndromic thread of diabetes and autoimmunity. Eur Rev Med Pharmacol Sci 19:3709-22.

116. Galassetti P, Riddell MC (2013) Exercise and type 1 diabetes (T1DM). Compr Physiol 3:1309-1336. doi: 10.1002/cphy.c110040

117. Pedersen BK, Saltin B (2015) Exercise as medicine - Evidence for prescribing exercise as therapy in 26 different chronic diseases. Scand J Med Sci Sport. doi: $10.1111 / \mathrm{sms} .12581$

118. West DJ, Campbell MD, Gonzalez JT, et al (2015) The inflammation, vascular repair and injury responses to exercise in fit males with and without Type 1 diabetes: an observational study. Cardiovasc Diabetol 14:71. doi: 10.1186/s12933-015-0235-y

119. Steppel JH, Horton ES (2003) Exercise in the Management of Type 1 Diabetes Mellitus. Rev Endocr Metab Dis 4:355-369. doi: 10.1023/A:1027302112655 


\section{Figure Captions}

\section{Figure 1.}

Graphical Abstract. The pillars to maximize exercise-benefits in the lifestyle of people with type 1 diabetes: properly modulating carbohydrates ingestion beforeduring-after exercise, strict monitoring of glucose and insulin, adequacy of healthcare professionals, and a comprehensive educational approach.

\section{Figure 2.}

Synoptic picture summarizing the metabolic and endocrine responses to moderate, constant-load exercise in healthy- and T1D-subjects.

Figure 3.

Scheme of the indications (nutritional and insulin adjustments) for maintaining glucose homeostasis during constant-load, moderate exercise in T1D-subjects according to the most reported guidelines $[85,89,90]$. 
Table 1.

Studies examining the effects of exercise interventions on T1D.

\section{Authors}

Subjects

Type of exercise

Main outcomes

Andersen et al. ${ }^{[91]}$

Adults with T1D

Adults with T1D

al. ${ }^{\text {[92] }}$

Campbell et al. $^{\text {[93] }}$

McAuley et al. $^{[94]}$

Adults with T1D on CSII

Luzi et al. ${ }^{[3]}$

Sherr et al. ${ }^{[95]}$

Martinez-

Ramonde et al. ${ }^{[96]}$

Adamo et al. ${ }^{[6]}$

Davey et al. ${ }^{[97]}$

Tunar et al. ${ }^{[98]}$
Diabetic adults from onet to 2-yr period

Adults with T1D on CSII + CGM

Adolescents with T1D

Adolescents and young subjects with T1D

Retrospective diary on PA programmes adherence

3 mo observational study on PA levels

Hyperinsulinemic euglycemic clamps during either resting or 45 min cycling on an ergometer@ -65\% VO $\mathrm{VO}_{2} \max$

Adolescents with

60 min treadmill walking @ $65-70 \%$ HRmax

12-wk of Pilates session
Isokinetic peak torque of dorsal/plantar flexion of ankle

Regression analysis on between autoimmunity markers (GAD, IA) and weekly energy expenditure (EE) derived from physical exercise
Torque loss at ankle and knee neg. correlates with neuropathy Torque correlates with
muscle volume

Preventing post-exercise hypoglycemia with $\downarrow$ basal insulin and $\downarrow$ prandial bolus insulin

Exercise-induced hypoglycemia was prevented only with $\uparrow$ insulin basal rate supplemental $\mathrm{CHO}$

$\downarrow$ autoimmunity and longer honeymoon in $\uparrow$ physycally active subjects

$\downarrow$ nocturnal hypoglycemia $\mathrm{w} /$ closed-loop insulin delivery, regardless of activity level in the midafternoon

$\uparrow$ PA allows better glycemic control, residual pancreatic mass and insulin requirements

$\uparrow$ PA allows better metabolic control and body composition, $\downarrow$ hypoglycemic events

No evidence of biphasic pattern of post-exercise risk of hypoglycemia

$\leftrightarrow$ HbAlc, $\uparrow$ peak power, 
Yardley et al. ${ }^{[99]}$

Adolescents and adults with T1D

Bally et al. ${ }^{[71]}$

Shetty et al. ${ }^{[100]}$

Davey et al. ${ }^{[101]}$

Yardley et al. ${ }^{[68]}$

Young adults with T1D

Guelfi et al. ${ }^{[69]}$

Iscoe et al. ${ }^{[70]}$

Harmer et al. ${ }^{[64]}$

Young adults with T1D

Young adults with T1D

Young adults with T1D T1D
RE on aerobically active subjects. 3 times/wk; 8RM x

7 exercise on weight machines

High-intensity intermittent training versus continuos moderate-intensity exercise

Trained athletes with measured during two sedentary days and during 2 days in which $45 \mathrm{~min}$ of afternoon continuous moderate-intensity exercise occurred either with or without intermittent highintensity exercise

Sprint training (cycling @ $130 \% \mathrm{VO}_{2}$ peak) for 7-wk.
PA recommendations for subjects with T1D.

READI study has not been completed yet.

$\downarrow$ Glucose disposal and $\uparrow$ flexibilityin highintensity intermittent training

Inverted U relationship between exercise intensity and glucose requirement

$\leftrightarrow$ CHO after 10 -s sprint to maintain euglycemia

RE before AE improves glucose stability dufing exercise and $\downarrow$

hypoglycemia postexercise

Decline in blood glucose in the early recovery is less with high-intensity intermittent exercise vs moderate one

$\downarrow$ Nocturnal hypoglycemia with intermittent highintensity exercise + moderate one

$\downarrow$ metabolic

destabilization (of lactate, $\mathrm{H}^{+}$,

glycogenolysis/glycolysis, and ATP) during intense exercise, $\uparrow$ Muscle 
oxidative metabolism

Komatsu et al. ${ }^{[80,}$ 102]

Veves et al. ${ }^{[103]} \quad$ Young adults with

Gusso et al. ${ }^{[104]}$

Salem et al. ${ }^{[105]}$

Codella et al. ${ }^{[8]}$

Herbst et al. ${ }^{[106]}$

Huber et al. ${ }^{[107]}$

Laaksonen et al. ${ }^{[108]}$ T1D

Children, adolescents, and young adults with T1D

Adolescents with T1D, T2D and obese

Adolescents with T1D
An islet-transplanted ultra endurance runner

Children and adolescents with T1D

Children and adolescents with T1D

Adults with T1D incremental aerobic exercising test on a motorized treadmill

Observational study between physically active and sedentary subjects

Evaluation of maximal aerobic capacity on acycle ergometer during submaximal exercise

Mixed exercise programs (AE+RE) 3 times/wk for 6 mo

Monitoring of glucose, insulin, autoimmunity and inflammatory markers before, during and after marathon periods
Self-reported regular physical activity

Two training sessions (lasting 90-120 min) per d (soccer, biking, hiking, swimming, ball games)

30-60 min moderate-intensity running 3-5 times/wk for 12$16 \mathrm{wk}$.
Aerobic capacity $20 \% \downarrow$ in T1D vs peer controls

Aerobic capacity $\leftrightarrow$ in physically active people with T1D

$\downarrow$ Exercise stroke volume response and $\downarrow$ aerobic capacity in diabetic adolescents

$\downarrow H b A 1 \mathrm{c}$, $\leftrightarrow$ hypoglycemic episodes, BMI improved, $\downarrow$ insulin requirements, dyslipidemia improved

Marathons were accompanied by marathon" period was accompanied by $\downarrow \mathrm{HbA} 1 \mathrm{c}$, $\downarrow$ exogenous insulin requirement, $\leftrightarrow$ autoimmune profile, with systemic inflammation

$\downarrow$ total cholesterol, $\downarrow$ lowdensity lipoprotein cholesterol, $\downarrow$ triglyceride levels

$\downarrow$ in mean insulin dosage, $\downarrow$ mean $\mathrm{HbA} 1 \mathrm{c}, \downarrow$ total ghrelin levels

Better body composition, $\leftrightarrow \mathrm{HbA} 1 \mathrm{c}$, better lipid profile

Abbreviations: $\uparrow=$ significant increase; $\downarrow=$ significant decrease; $\leftrightarrow=$ no changes; AE $=$ aerobic exercise; $\mathrm{CHO}=$ carbohydrates; $\mathrm{d}=$ day $; \mathrm{HR}=$ heart rate; $\min =$ minutes; $\mathrm{mo}=$ month; $\mathrm{PA}=$ physical activity; $\mathrm{RE}=$ resistance exercise; $1 \mathrm{RM}=$ repetition maximum; $\mathrm{s}=$ second; $\mathrm{T} 1 \mathrm{D}=$ type 1 diabetes; $\mathrm{VO}_{2}=$ oxygen uptake; $\mathrm{yr}=$ year; wk $=$ week. 
Table 2.

Differences between sedentary and active subjects with type 1 diabetes

sedentary

active

body composition ${ }^{[6,109]}$

blood glucose control ${ }^{[6,8,110,111,96 \text {, }}$

$=/-$

$=/+$

hypoglycemic episodes $[6,8,48,97,93]$

$=/-$

hyperglycemic episodes ${ }^{[55,56,113]}$

$=/-$

$+$

insulin doses ${ }^{[6,8,93]}$

insulin sensitivity ${ }^{[7,31,46,84]}$

blood lipid profile ${ }^{[111,112]}$

$=/-$

$=/+$

autoimmunity $[3,114,115]$

$-\quad=/+$

inflammation ${ }^{[96,115-118]}$

$-$

$=/+$

psychological well-being ${ }^{[112,119]}$

$=/-$

$+$

cardiorespiratory fitness $[80,102,104]$

$=$ stable

+ improvement

- deterioration 

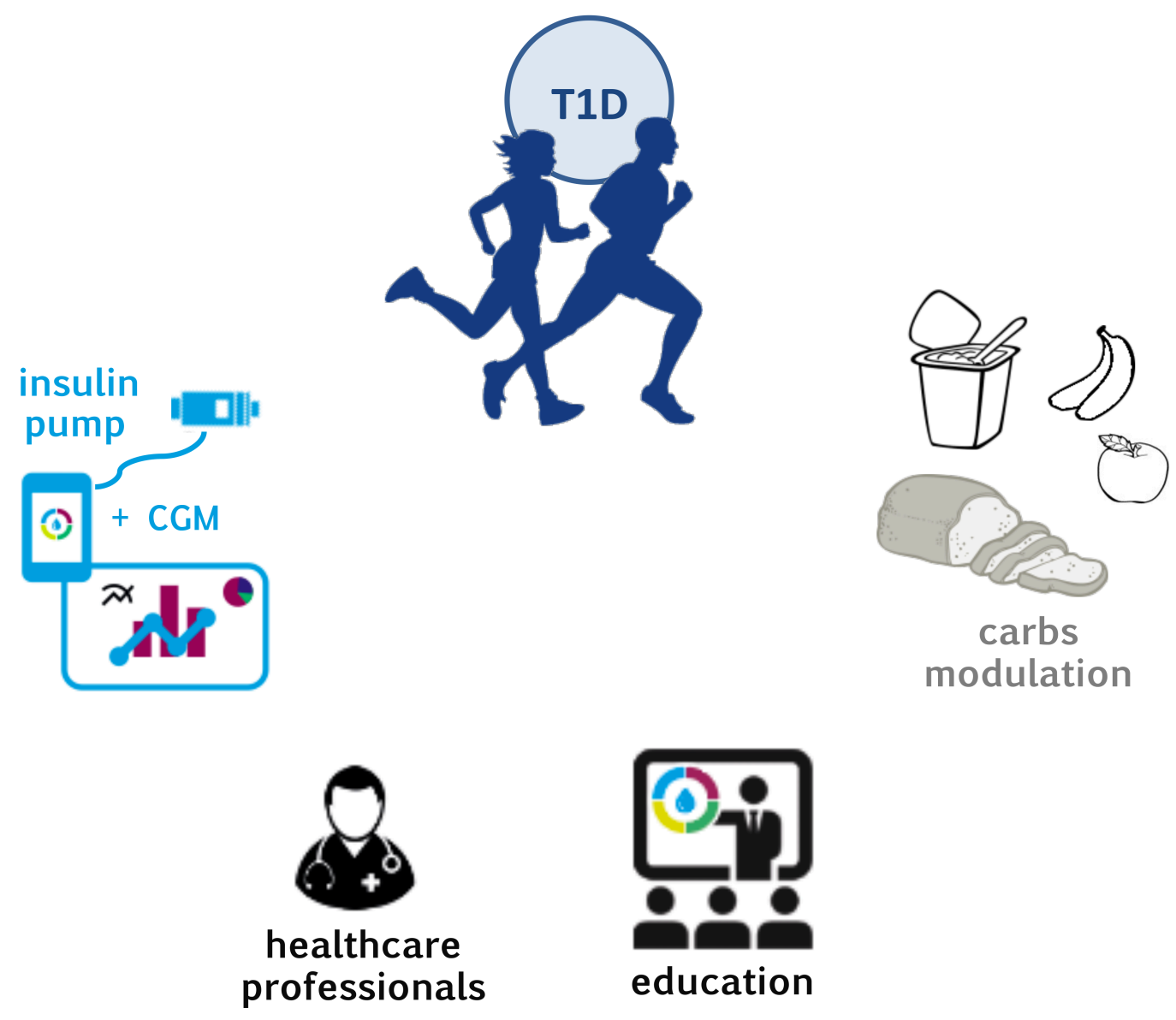

Figure 1.

Graphical Abstract. The pillars to maximize exercise-benefits in the lifestyle of people with type 1 diabetes: properly modulating carbohydrates ingestion beforeduring-after exercise, strict monitoring of glucose and insulin, adequacy of healthcare professionals, and a comprehensive educational approach. 

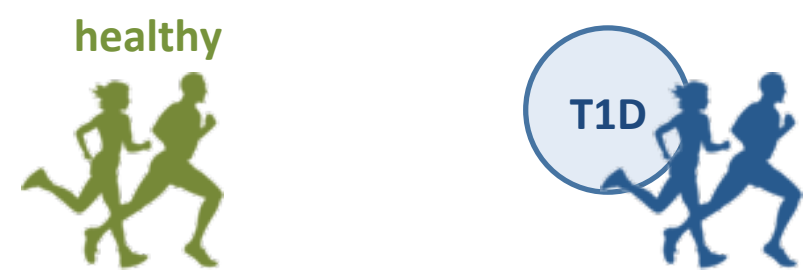

pancreas

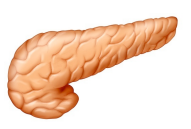

insulin

glucagon

glycogen

glucose

liver
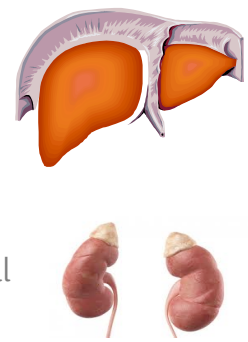

catecolamines

glands

adipose

tissue

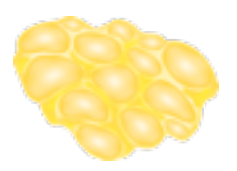

NEFA

skeletal muscle

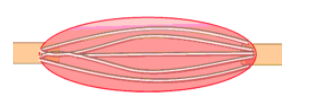

glucose transporters insulin receptors citokynes euglycemia is maintained through the increase of glucagon secretion and decrease of insulin secretion. glycemic responses depend on exercise modality, carbs ingestion, location and amount of insulin injected. Hypoglycemia is most common. hepatic glucose output is increased via glycogenolysis and gluconeogenesis endogenous glucose production is inadequate epinephrine increases and stimulates muscle and hepatic glycogenolysis.

Norepinephrine increases and stimulates

hepatic glycogenolysis; reduces muscular glucose uptake; decreases insulin secretion. Cortisol increases and induce lipolysis and gluconeogenesis.

during prolonged aerobic exercise, lipid oxidation is augmented. During highintensity exercise (> $60 \mathrm{VO}_{2}$ max), fat oxidation decreases counter-regulatory hormone responses may be abrnomal or lost, causing hypoglycemia muscle glucose uptake rises, matching the increased glucose production. Insulin sensitivity augments due to increased GLUT-4 translocation to the cell surface contractile capacity may be impaired and morphological abnormalities may be detected in the diabetic skeletal muscle exercise-induced lipolysis is attenuated due to high (exogenous) insulin levels

\section{Figure 2.}

Synoptic picture summarizing the metabolic and endocrine responses to moderate, constant-load exercise in healthy- and T1D-subjects. 


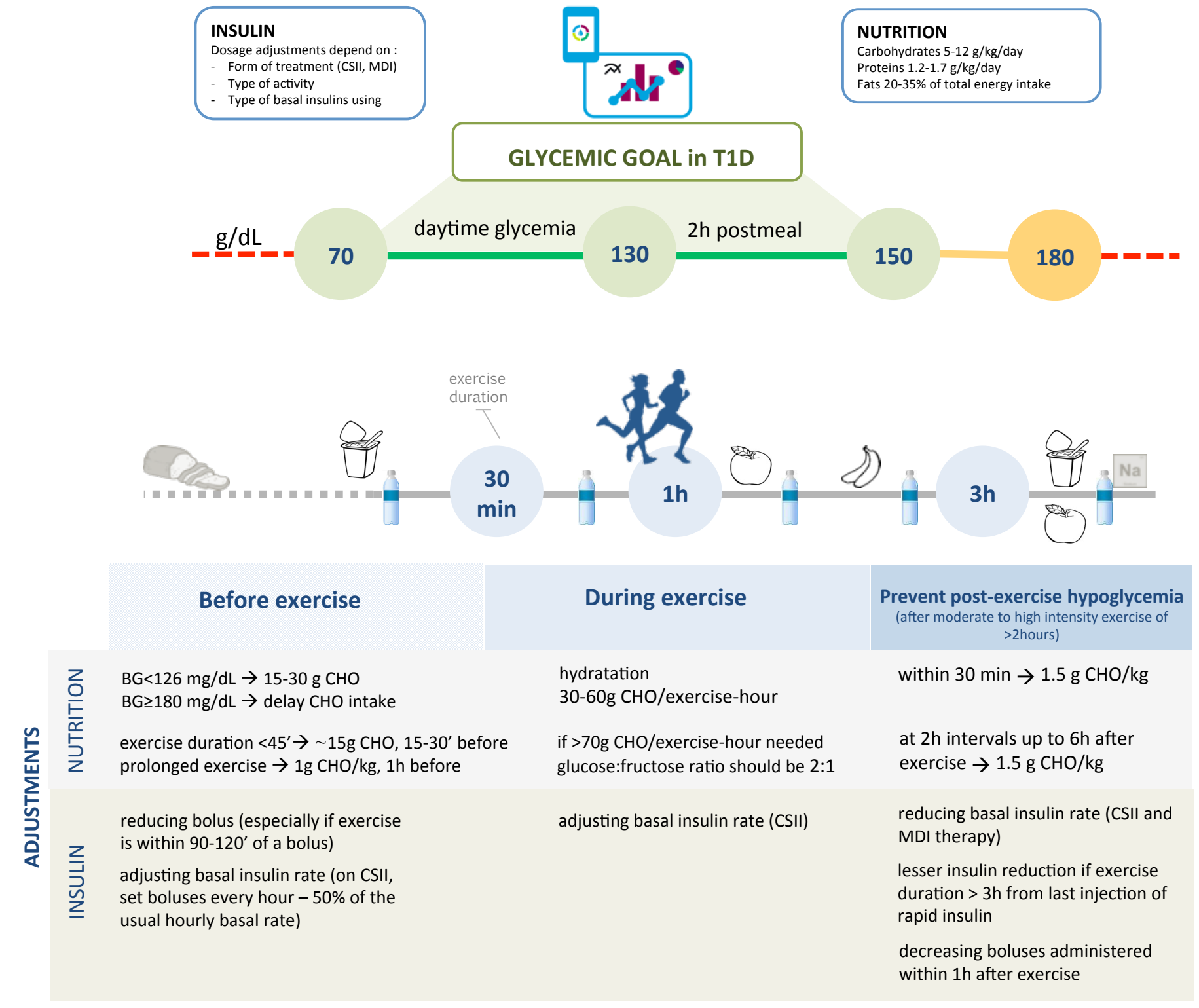

Figure 3.

Scheme of the indications (nutritional and insulin adjustments) for maintaining glucose homeostasis during constant-load, moderate exercise in T1D-subjects according to the most reported guidelines $[85,89,90]$. 